\title{
Urinary Excretion of Vitamin K Metabolites in Term and Preterm Infants: Relationship to Vitamin K Status and Prophylaxis
}

\author{
DOMINIC JON HARRINGTON, PAUL CLARKE, DAVID J. CARD, SIMON J. MITCHELL, AND MARTIN J. SHEARER \\ The Nutristasis Unit [D.J.H., D.J.C., M.J.S.], St. Thomas' Hospital, London SE1 7EH, United Kingdom; Norfolk and Norwich University \\ Hospitals [P.C.], NHS Foundation Trust, Norwich NR4 7UY, United Kingdom; Newborn Intensive Care Unit [S.J.M.], St. Mary's \\ Hospital, Manchester M13 9WL, United Kingdom
}

\begin{abstract}
Little is known about the metabolic turnover and excretion of vitamin $\mathrm{K}$ in healthy newborn infants and the metabolic consequences of prophylactic regimens designed to protect against vitamin $\mathrm{K}$ deficiency bleeding (VKDB). We measured the excretion of two urinary metabolites $(\leq 24 \mathrm{~h})$ of vitamin $\mathrm{K}(5 \mathrm{C}$ - and $7 \mathrm{C}$ aglycones $)$ in term infants before $(n=11)$ and after $(n=5)$ a 1000 $\mu \mathrm{g}$ i.m. dose of vitamin $\mathrm{K}_{1}\left(\mathrm{~K}_{1}\right)$ and in preterm infants after $200 \mu \mathrm{g}$ i.m. $(n=4), 500 \mu \mathrm{g}$ i.m. $(n=4)$, or $200 \mu \mathrm{g}$ i.v. $(n=5)$. In preterm infants, we also measured serum $\mathrm{K}_{1}$, vitamin $\mathrm{K}_{1}$ 2,3-epoxide, and PIVKA-II at $5 \mathrm{~d}$ postpartum. Before prophylaxis, the rate of $5 \mathrm{C}$ - and $7 \mathrm{C}$-aglycone excretion was 25 times lower than adults, reflecting low vitamin $\mathrm{K}$ stores at birth. After prophylaxis, the excretion rate correlated to $\mathrm{K}_{1}$ dose $(r=0.6)$ but was two orders of magnitude lower than that in adults, probably reflecting the immaturity of neonatal catabolism. All term and 10 of 13 preterm infants mainly excreted 5C-aglycone. We present evidence that increased excretion of the 7C-aglycone was associated with metabolic overload because of the exposure to high-tissue $\mathrm{K}_{1}$ concentrations. Measurement of the $5 \mathrm{C}$ - and 7C-aglycones may facilitate longitudinal studies of vitamin $\mathrm{K}$ status in neonates and aid the development of improved prophylactic regimens. (Pediatr Res 68: 508-512, 2010)
\end{abstract}

$\mathrm{T}_{\mathrm{f}}^{\mathrm{k}}$ he major naturally occurring $\mathrm{K}$ vitamins are the plant form vitamin $\mathrm{K}_{1}$ (abbreviated $\mathrm{K}_{1}$ ) and the multiple forms of vitamins $\mathrm{K}_{2}$ (abbreviated $\mathrm{K}_{2}$ ), mainly of bacterial origin. Under the IUPAC nomenclature, vitamin $\mathrm{K}_{1}$ is called phylloquinone and vitamins $\mathrm{K}_{2}$ are called menaquinones. Vitamin $\mathrm{K}$ is a cofactor for the posttranslational modification of specific peptide-bound glutamate (Glu) residues to $\gamma$-carboxyglutamate (Gla) within vitamin K-dependent proteins of which the procoagulant factors II, VII, IX, and X are essential for the maintenance of hemostasis (1).

During the first 6 mo of life, breast-fed infants have an increased susceptibility of developing vitamin $\mathrm{K}$ deficiency. Reasons for this are multifactorial, but prime physiologic factors are an inefficient placental transport of vitamin $\mathrm{K}$ antenatally (2) and low concentrations of $\mathrm{K}_{1}$ in human milk (3) leading to daily intakes in breast-fed neonates of the order of $1-2 \mu \mathrm{g} / \mathrm{d}$ compared with $80-120 \mu \mathrm{g} / \mathrm{d}$ in adults (4). Neonatal concentrations of the hepatic enzymes $\gamma$-glutamyl carboxylase (GGCX) and vitamin $\mathrm{K}_{1}$ 2,3-epoxide reductase (VKOR) may also be suboptimal (5), thus preventing efficient

Received March 29, 2010; accepted August 10, 2010.

Correspondence: Dominic Jon Harrington, Ph.D., The Centre for Haemostasis and Thrombosis, 1st Floor North Wing, St. Thomas' Hospital, Westminster Bridge Road, London SE1 7EH, United Kingdom; e-mail: dominic.harrington@gsts.com recycling of vitamin $\mathrm{K}(6)$. This premise is supported by the known immaturity of other hepatic enzyme systems in this population (7). In some infants, a nutritional lack of vitamin $\mathrm{K}$, sometimes combined with pathological factors, results in a potentially life-threatening bleeding disorder known as vitamin $\mathrm{K}$ deficiency bleeding (VKDB) (8). Therefore, many countries protect against VKDB by routinely supplementing all infants with vitamin $\mathrm{K}$ after delivery.

There is presently no consensus on optimal regimens for vitamin $\mathrm{K}$ prophylaxis against $\operatorname{VKDB}(9,10)$. In particular, preterm infants are potentially exposed to high tissue concentrations of vitamin $\mathrm{K}$ through the adoption of prophylaxis regimens initially intended for term infants and from addition of excessive vitamin $\mathrm{K}$ to parenteral nutrition feeds (11-13). The reported association between i.m. injection of vitamin $\mathrm{K}$ at birth and childhood cancer (14) has now largely been refuted (15); however, the suprapharmacological vitamin $\mathrm{K}$ levels that follow excessive prophylaxis may conceivably have adverse consequences, as yet unrecognized.

Traditional coagulation tests for assessing vitamin $\mathrm{K}$ status are both nonspecific and insensitive, whereas reference ranges in neonates are poorly defined $(8,16)$. More discriminating tests include measurements of circulating $\mathrm{K}_{1}$ and undercarboxylated species of Gla proteins, collectively called proteins induced by vitamin $\mathrm{K}$ absence (PIVKA), that are released into the bloodstream from their site of synthesis in early stages of vitamin $\mathrm{K}$ insufficiency. In this study, for the preterm cohort only, the sensitive functional marker undercarboxylated factor II (PIVKA-II) had been measured at birth (cord blood) and at $5 \mathrm{~d}$ after vitamin $\mathrm{K}$ prophylaxis. Measurements of serum $\mathrm{K}_{1}$ (and its epoxide metabolite, $\mathrm{K}_{1} \mathrm{O}$ ) had also been made in the preterm cohort at $5 \mathrm{~d}$.

The catabolism of $\mathrm{K}_{1}$, MK-4, and the $\mathrm{K}_{2}$ series leads in each case to the excretion of identical metabolites via the urine and bile $(17,18)$. An assay for the determination of the major urinary metabolites of vitamin $\mathrm{K}$ has been developed (18) and used to demonstrate that excretion of the 2-methyl-3-(5'-

\footnotetext{
Abbreviations: 5C-aglycone, 2-methyl-3-(3'-3'-carboxymethylpropyl)-1,4naphthoquinone; 7C-aglycone, 2-methyl-3-(5'-carboxy-3'-methyl-2'-pentenyl)1,4-naphthoquinone metabolite; Gla, $\gamma$-carboxyglutamate residues; $\mathbf{K}_{\mathbf{1}}$, vitamin $\mathrm{K}_{1}$ or phytomenadione; $\mathbf{K}_{\mathbf{1}} \mathbf{O}$, vitamin $\mathrm{K}_{1}$ 2,3-epoxide; $\mathbf{K}_{\mathbf{2}}$, menaquinones; PIVKA-II, undercarboxylated factor II; VKOR, vitamin $\mathrm{K}_{1}$ 2,3-epoxide reductase; VKDB, vitamin $\mathrm{K}$ deficiency bleeding
} 
carboxy-3'-methyl-2'-pentenyl)-1,4-naphthoquinone metabolite (7C-aglycone) and the 2-methyl-3-(3'-3'-carboxymethylpropyl)-1,4-naphthoquinone metabolite (5C-aglycone) reflects dietary vitamin $\mathrm{K}$ intake in healthy adults (19). This study aimed i) to determine whether newborn infants metabolize vitamin $\mathrm{K}$ by the same pathway as adults and ii) to assess the extent of this excretion before and after vitamin $\mathrm{K}$ prophylaxis. In this second part, we could also relate urinary metabolite excretion to prophylactic dose and, in preterms, to serum concentrations of $\mathrm{K}_{1}$ and $\mathrm{K}_{1} \mathrm{O}$ and to the functional hepatic marker of vitamin $\mathrm{K}$ status, PIVKA-II. The $\mathrm{K}_{1}$ and $\mathrm{K}_{1} \mathrm{O}$ measurements are relevant to interpretation of both the rate of metabolism of vitamin $\mathrm{K}$ and to hepatic recycling, whereas PIVKA-II measurements are relevant because they reflect the vitamin $\mathrm{K}$ status of the liver, where both vitamin $\mathrm{K}$-dependent proteins and the urinary metabolites are synthesized.

\section{METHODS}

Subjects. All infants were recruited at Hope Hospital, Salford, United Kingdom. Written informed parental consent was obtained before enrollment, and the study was approved by North Manchester Research Ethics Committee.

Term infant recruitment and specimen collection. Women admitted to hospital in early labor at term ( $\geq 37$ wk gestation) were approached for consent for the study between March and July 2003. Eligible infants were born to parents who agreed to their infant receiving the standard recommended prophylactic K1 regimen of $1 \mathrm{mg}$ by i.m. injection of Konakion Neonatal ${ }^{\circledR}$ (Roche, Basel, Switzerland), a Cremophor-based synthetic K1 preparation, but delayed for up to $24 \mathrm{~h}$ after delivery to enable urine to be collected before prophylaxis. Infants were excluded from participation if there had been maternal treatment during pregnancy with certain anticonvulsants (carbamazepine, phenytoin, or phenobarbital), cephalosporin antibiotics, or warfarin. These drugs antagonize vitamin $\mathrm{K}$ and may cause early onset neonatal VKDB $(<24 \mathrm{~h}$ of age). Other exclusion criteria were marked bruising at birth, major congenital abnormality, maternal antiplatelet antibodies, history of alloimmune thrombocytopenia, and antenatally diagnosed intracranial hemorrhage.

A sterile neonatal urine bag (U-Bag; Hollister Inc., Libertyville, IL) was attached to each infant within $15 \mathrm{~min}$ of delivery. Routine prophylactic vitamin $\mathrm{K}_{1}$ administration was delayed until a first urine sample had been collected. When no urine was obtained during the first postnatal day, vitamin $\mathrm{K}$ was given at $24 \mathrm{~h}$ of age. We aimed to collect all urine voided during the 24-h period after vitamin $\mathrm{K}$ prophylaxis and to obtain further spot urine samples on all subsequent days that the neonate remained in hospital. Samples were protected from light and stored at $-40^{\circ} \mathrm{C}$ and then periodically couriered on dry ice to St. Thomas' Hospital for analysis. We anticipated that urine samples would be successfully obtained from half of the enrolled infants and determined a priori to enroll a pragmatic study sample size of 50 term infants.

Preterm infant recruitment and specimen collection. Preterm infants were eligible to participate in this study if admitted to the Neonatal Intensive Care Unit at Hope Hospital between December 2002 and October 2003 after delivery at $<32 \mathrm{wk}$ gestation. They comprised a subgroup of infants enrolled into a clinical trial comparing vitamin $\mathrm{K}$ status of preterm infants after three regimens of prophylaxis (20). The same exclusion criteria applied as for the term infants. Infants were randomly allocated to receive one of the following doses of Konakion Neonatal vitamin $\mathrm{K}_{1}: 200 \mu \mathrm{g}$ i.m., $500 \mu \mathrm{g}$ i.m., or $200 \mu \mathrm{g}$ i.v. Because preterm infants are potentially at increased risk of VKDB $(13,20)$, vitamin K prophylaxis was not delayed. We aimed to collect all urine voided in the first week of life, but at least for $48 \mathrm{~h}$ after vitamin $\mathrm{K}_{1}$ administration. Attendant neonatal nursing staff collected the urine samples using either sterile preterm-sized urine bags (U-Bag Premie; Hollister Inc., Libertyville, IL) or via sterile cotton wool pads placed in the infant's diaper. To minimize evaporative losses, infants were nursed in incubators with high humidity during the first few days of life (21).

To compare with previous studies $(11,12)$, serum $\mathrm{K}_{1}$ levels were determined in the preterm infants on d 5 postpartum. Peripheral venous blood ( 2 $\mathrm{mL}$ ) was collected in plain tubes at $5 \mathrm{~d}$ of age. Samples were centrifuged and sera separated. All samples were protected from light, frozen, and stored at $-40^{\circ} \mathrm{C}$ until transportation on dry ice to St. Thomas’ Hospital for analysis.
Assessment of vitamin $\mathrm{K}$ status. The urinary metabolites of vitamin $\mathrm{K}$ (5C- and 7C-aglycones) were determined by HPLC with redox mode electrochemical detection as previously described (18). This assay gives excellent linearity ( $r^{2}$ typically $\left.\geq 0.999\right)$ with an on-column detection limit of $<1 \mathrm{pg}$. Interassay precision is $<10 \%$. The rate of $5 \mathrm{C}$ - and $7 \mathrm{C}$-aglycone excretion $(\mathrm{ng} / \mathrm{h})$ before prophylaxis was determined and expressed as a function of infant weight $(\mathrm{kg})$.

Serum $\mathrm{K}_{1}$ concentrations were determined using a modified HPLC method with postcolumn chemical reduction and fluorescence detection (22). The limit of quantification was $0.05 \mu \mathrm{g} / \mathrm{L}$. In normal healthy normolipemic adults, the fasting reference range for $\mathrm{K}_{1}$ is 0.17 to $0.68 \mu \mathrm{g} / \mathrm{L}$ (median, $0.37 \mu \mathrm{g} / \mathrm{L}$ ). The assay performance was assured through participation in the Vitamin $\mathrm{K}$ External Quality Assurance Scheme (KEQAS). Vitamin $\mathrm{K}_{1}$ 2,3-epoxide $\left(\mathrm{K}_{1} \mathrm{O}\right)$, a metabolic by-product of Gla synthesis that is efficiently salvaged by VKOR to regenerate the metabolically active hydroquinone form of $K_{1}$ in adults, was also determined in serum (limit of quantification $=0.12 \mu \mathrm{g} / \mathrm{L}$ ). Serum concentrations of $\mathrm{K}_{1} \mathrm{O}$ are typically $<0.12 \mu \mathrm{g} / \mathrm{L}$.

The net activity of vitamin $\mathrm{K}$ with respect to the coagulation function of vitamin $\mathrm{K}$ was determined through the measurement PIVKA-II. Serum PIVKA-II concentrations were determined using a MAb (C4B6) to PIVKA-II in an ELISA format that is conformation specific such that it binds only undercarboxylated species of prothrombin and is not cross-reactive with fully carboxylated native prothrombin $(23,24)$. Results are expressed as arbitrary units (AU) per mL, where $1 \mathrm{AU}$ is equivalent to $1 \mu \mathrm{g}$ of multiple PIVKA-II species. Using this assay, the upper limit of the reference range for PIVKA-II in adults is $<0.2 \mathrm{AU} / \mathrm{mL}$.

Statistical analysis. Statistical analyses were performed using Minitab Statistical Software version 13.1 (Minitab Inc., State College, PA). The correlation between prophylactic $\mathrm{K}_{1}$ dose and urinary metabolite excretion was examined using Spearman's coefficient. Cumulative urinary excretion of vitamin $\mathrm{K}$ metabolites before and after vitamin $\mathrm{K}$ prophylaxis was plotted as a function of time according to GA, route, dose, and percentage dose excreted. Statistical significance was defined a priori as $p<0.05$ (two tailed).

\section{RESULTS}

Fifty term infants were recruited, and in 30 of them, at least one suitable urine sample was collected. Reasons for noncollection $(n=20)$ included early discharge from hospital (11 infants), protocol violation (two infants: one received $\mathrm{K}_{1}$ orally and one received $\mathrm{K}_{1}$ at delivery), mothers declined further participation in the study (seven infants). The median (range) GA and birth weight were 40 (37-41) wk and 3.300 $(1.880-4.660) \mathrm{kg}$. Urine was collected from 26 preterm infants. Their median (range) GA and birth weights were 29 completed weeks (22-31 wk) and $1.030 \mathrm{~kg}(0.454-1.892 \mathrm{~kg})$.

Urinary $5 C$ - and $7 C$-aglycone excretion by term infants before $K_{1}$ prophylaxis. Urine was successfully collected before $\mathrm{K}_{1}$ prophylaxis from 11 of the 30 term infants. Reasons for the relatively low rate of urine collection on $\mathrm{d} 1$ included missed collections, leaking or detached urine bags, no urine passed in the first $24 \mathrm{~h}$ postnatal, and contamination of the specimen by meconium.

The 5C- and 7C-aglycones were detected in the urine of all 11 term infants; in all samples, the 5C-aglycone was the most abundant metabolite (typical $5 \mathrm{C}: 7 \mathrm{C}$ ratio $=2: 1$ ). The rate of $5 \mathrm{C}$ - and $7 \mathrm{C}$-aglycone excretion estimated from the analysis of samples collected over a mean of 17.8 (range, 6.6-26) h varied from 0.01 to 0.35 (mean, 0.14 ) ng/kg/h. When compared with data from our previous studies in young adults, this rate of excretion was 25 -fold lower than that $(3.6 \mathrm{ng} / \mathrm{kg} / \mathrm{h})$ in young men and women eating a self-selected diet and 14-fold lower than that $(2.1 \mathrm{ng} / \mathrm{kg} / \mathrm{h})$ in adults residing in a metabolic unit fed a $\mathrm{K}_{1}$-restricted diet of $11 \mu \mathrm{g} / \mathrm{d}$ for $15 \mathrm{~d}$ (19), (Fig. 1).

Urinary $5 C$ - and $7 C$-aglycone excretion by term and preterm infants after $K_{I}$ prophylaxis. Complete collections of all urine voided in at least the 24 -h period after $\mathrm{K}_{1}$ prophylaxis 


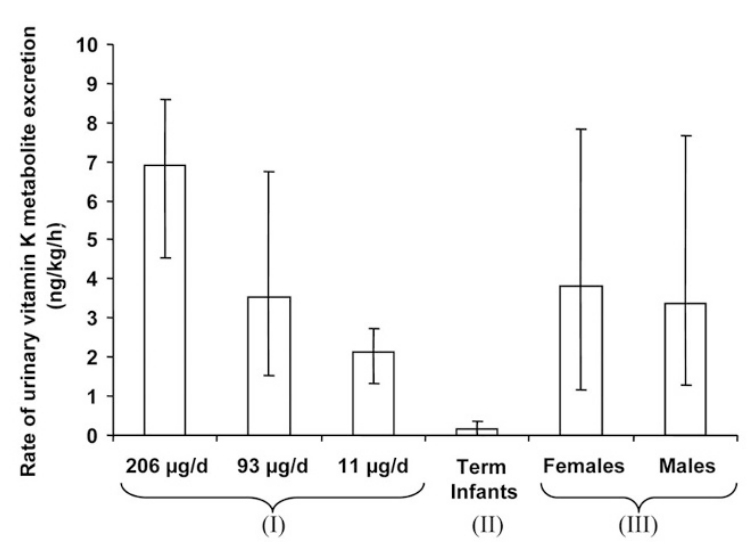

Figure 1. Hourly rate of 5C-and 7C-aglycone urinary vitamin $\mathrm{K}$ metabolite excretion ( $\mathrm{ng} / \mathrm{kg}$ body weight) for (I) nine adult subjects resident in a metabolic unit-fed diets containing known amounts of vitamin $\mathrm{K}_{1}$ equivalent to a high $(206 \mu \mathrm{g} / \mathrm{d})$, a typical $(93 \mu \mathrm{g} / \mathrm{d})$, and a low $(11 \mu \mathrm{g} / \mathrm{d})$ daily intake*, (II) 11 newborn term infants before vitamin $\mathrm{K}$ prophylaxis, and (III) young healthy free-living adults eating a self-select diet (57 females and 107 males).

suitable for 5C- and 7C-alglycone analysis were obtained from five term infants (three males and two females) and 13 preterm infants (eight males and five females; Table 1). Both aglycones were excreted by all preterm infants.

When $\mathrm{K}_{1}$ had been given via the i.m. route, urinary vitamin $\mathrm{K}$ metabolite excretion 24 to $48 \mathrm{~h}$ postprophylaxis correlated to the administered dose $(r=0.6, p=0.03)$. The rate of $5 \mathrm{C}$ and $7 \mathrm{C}$-aglycone excretion began to increase between 8 and $15 \mathrm{~h}$ postprophylaxis. In all term infants and in 10 of 13 preterm infants, there was a temporal increase in the proportional excretion of the $5 \mathrm{C}$-aglycone relative to the $7 \mathrm{C}$ aglycone. A representative HPLC chromatogram illustrating urinary $5 \mathrm{C}$ - and $7 \mathrm{C}$-aglycone excretion by a term infant $2 \mathrm{~d}$ after $\mathrm{K}_{1}$ prophylaxis (500 $\mu \mathrm{g}$ i.m.) is shown in Figure $2 \mathrm{~A}$.

Three preterm infants mainly excreted the less extensively catabolized 7C-aglycone. These infants were of similar GA and birth weight as the 10 preterm infants who predominantly excreted the 5C-aglycone. An HPLC chromatogram illustrating predominant urinary excretion of the $7 \mathrm{C}$-aglycone by a preterm infant (29 wk GA) $1 \mathrm{~d}$ after $\mathrm{K}_{1}$ prophylaxis $(200 \mu \mathrm{g}$, i.v.) is shown in Figure $2 B$. With all four prophylactic regimens, the median proportion of administered $\mathrm{K}_{1}$ excreted as urinary metabolites in the $48 \mathrm{~h}$ after prophylaxis was 0.03 $(0.02-0.03) \%$, with the greatest range in those infants who received $200 \mu \mathrm{g}$ of $\mathrm{K}_{1}$ via the i.v. route (Table 1).

We were only able to collect serial urine samples at short time intervals during the first $24 \mathrm{~h}$ after vitamin $\mathrm{K}_{1}$ prophylaxis in two infants comprising one male infant from the 200
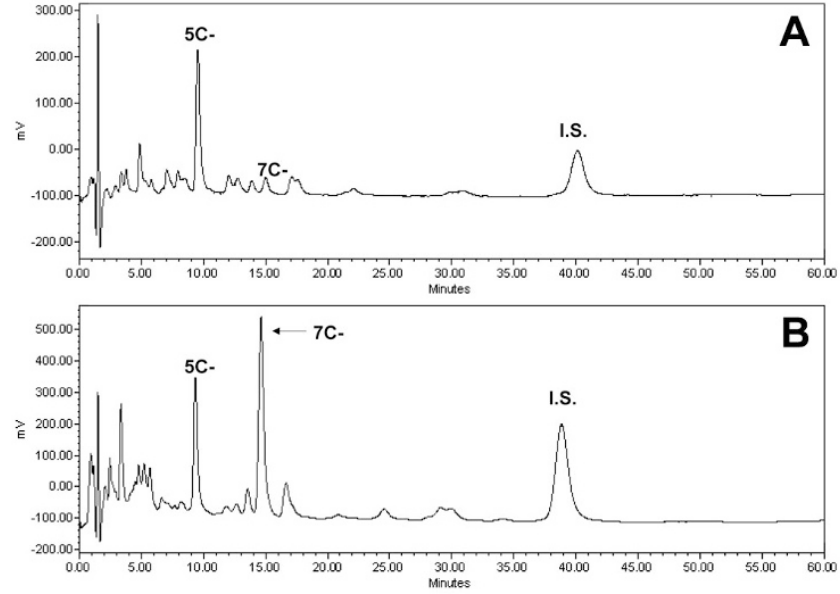

Figure 2. A, Representative chromatogram obtained for a urinary vitamin $\mathrm{K}$ metabolite extract from a term infant $2 \mathrm{~d}$ after vitamin $\mathrm{K}_{1}$ prophylaxis $(500 \mu \mathrm{g}$ i.m.). $B$, A chromatogram obtained for a urinary vitamin $\mathrm{K}$ metabolite extract from a preterm infant ( $29 \mathrm{wk}$ GA and birth weight $0.92 \mathrm{~kg}$ ) $1 \mathrm{~d}$ after vitamin $\mathrm{K}_{1}$ prophylaxis $(200 \mu \mathrm{g}$, i.v. $)$ in which levels of the $7 \mathrm{C}$-aglycone exceeded those of the $5 \mathrm{C}$-aglycone.

$\mu$ g i.m. group (27 wk GA, weight $1.10 \mathrm{~kg} ; 8$ urine samples) and one male infant from the $200 \mu \mathrm{g}$ i.v. group (29 wk GA, weight $0.92 \mathrm{~kg} ; 11$ urine samples). As shown in Figure 3, the time courses of metabolite excretion were similar up to $15 \mathrm{~h}$ after which the excretion rate in the infant who received i.v. prophylaxis increased dramatically. The cumulative total urinary vitamin K metabolite excretion $>24 \mathrm{~h}$ was $55 \mathrm{ng}$ and 424 ng in the i.m. and i.v. preterm infants, respectively (Fig. 3).

Relationship between pattern of aglycone excretion and serum concentrations of $K_{I}$ and $K_{I} O$. Five days after $K_{1}$ prophylaxis, serum $\mathrm{K}_{1}$ concentrations in the preterm infants were $182(154-225) \mu \mathrm{g} / \mathrm{L}, 100(74-207) \mu \mathrm{g} / \mathrm{L}$, and $86(34-$ 260) $\mu \mathrm{g} / \mathrm{L}$ in the $500 \mu \mathrm{g}$ i.m., $200 \mu \mathrm{g}$ i.m., and $200 \mu \mathrm{g}$ i.v. groups, respectively. Preterm infants who mainly excreted the 5C-aglycone had undetectable serum $\mathrm{K}_{1} \mathrm{O}(<0.12 \mu \mathrm{g} / \mathrm{L})$. Conversely, the three preterm infants who predominately excreted the 7C-aglycone (comprising two fourth preterms from the $500 \mu \mathrm{g}$ i.m. group and one fifth preterms from the $200 \mu \mathrm{g}$ i.v. group) had detectable $\mathrm{K}_{1} \mathrm{O}(16,51$, and $14 \mu \mathrm{g} / \mathrm{L}$, respectively).

Serum PIVKA-II levels. PIVKA-II was below the limit of detection $(<0.2 \mathrm{AU} / \mathrm{mL})$ in all preterm infants.

\section{DISCUSSION}

This is the first study to show that term and preterm infants catabolize $\mathrm{K}_{1}$ in a manner analogous to healthy adults. As in healthy adults, the $5 \mathrm{C}$-aglycone was the main metabolite

Table 1. Total (5C-and 7C-aglycone) urinary excretion of vitamin $K$ metabolites in preterm and term infants in the 24-h period immediately after vitamin $K$ administration according to dosage and route

\begin{tabular}{cccccc}
\hline $\begin{array}{c}\text { GA, median } \\
\text { (range) }\end{array}$ & $\begin{array}{c}\text { Route of } \\
\text { prophylaxis }\end{array}$ & $\begin{array}{c}\text { Dose } \\
(\mu \mathrm{g})\end{array}$ & $n$ & $\begin{array}{c}\text { Total 24 h excretion \%,* } \\
\text { median (range), (ng) }\end{array}$ & $\begin{array}{c}\text { Dose excreted, } \\
\text { median (range) }\end{array}$ \\
\hline Preterm 26 (24-29) & i.m. & 200 & 4 & $40(25-324)$ & $0.02(0.01-0.16)$ \\
Preterm 25 (24-30) & i.m. & 500 & 4 & $128(117-229)$ & $0.03(0.02-0.05)$ \\
Term 39 (39-40) & i.m. & 1000 & 5 & $295(72-1033)$ & $0.03(0.01-0.10)$ \\
Preterm 28 (25-30) & i.v. & 200 & 5 & $66(7-1029)$ & $0.03(<0.01-0.51)$ \\
\hline
\end{tabular}

\footnotetext{
* 5C- and 7C-aglycone.
} 


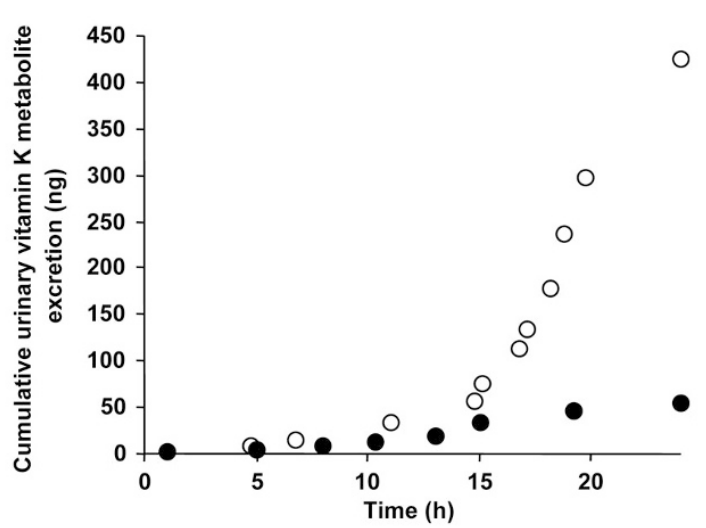

Figure 3. Comparison of urinary vitamin $\mathrm{K}$ metabolite excretion (5C- and 7C-aglycone) by two preterm infants during the 24-h period after $\mathrm{K}_{1}$ prophylaxis. - Male (27 wk GA and birth weight $1.10 \mathrm{~kg}$ ) given $200 \mu \mathrm{g}$ i.m. of $\mathrm{K}_{1}$; $\bigcirc$, male ( 29 wk GA and birth weight $0.92 \mathrm{~kg}$ ) given $200 \mu \mathrm{g}$ i.v. of $\mathrm{K}_{1}$.

excreted by all term infants and the majority of preterm infants before and after receiving vitamin $\mathrm{K}$ prophylaxis. However, after prophylaxis, three preterm infants who had attained the highest peak serum concentrations of $\mathrm{K}_{1}$ (and in whom $\mathrm{K}_{1} \mathrm{O}$ was also detectable) all primarily excreted the less extensively metabolized 7C-aglycone.

Compared with our earlier metabolite studies, the rate of $5 \mathrm{C}$ - and $7 \mathrm{C}$-aglycone excretion by term infants before $\mathrm{K}_{1}$ prophylaxis was far lower than in healthy young adults (25fold) or in adults fed with a $\mathrm{K}_{1}$-restricted diet of $11 \mu \mathrm{g} / \mathrm{d}$ for $15 \mathrm{~d}$ (14-fold) (19). This finding is in keeping with the notion that infants are born with vitamin $\mathrm{K}$ insufficiency as evidenced by low $K_{1}$ and $K_{2}$ concentrations in plasma (2) and liver (25) of fetuses and neonates. However, it does not discount that low urinary output may also reflect an immaturity of the enzymic pathway leading to vitamin $\mathrm{K}$ catabolism. Despite the low liver stores at birth, detectable circulatory levels of PIVKA-II are present only in a minority of newborns $(6,8,20)$. PIVKA-II was undetectable in all preterm infants in this study showed that their vitamin $\mathrm{K}$ status was sufficient for the efficient functional $\gamma$-carboxylation of hepatic coagulation factors.

In healthy adults, the 5C-aglycone is the predominant excretory product, with a typical $5 \mathrm{C}: 7 \mathrm{C}$ aglycone ratio of $4: 1$ $(18,19)$. In addition, term infants in this study predominately excreted the 5C-aglycone metabolite in urine, albeit with a reduced ratio of 2:1 (we were unable to collect urine before prophylaxis from any preterm infants or from term infants considered to be at increased risk of VKDB).

The low proportion of enrolled infants having one or more analyzable sample reflects practical difficulties in obtaining urine specimens from newborns. The challenge of obtaining multiple urine samples from well-term infants during the first days of life was significant. Frequent passage of meconium caused many contaminated bag specimens; the repeated application of urine bags led to many mothers declining further involvement with the study. Collection of preterm urine proved more successful because of the skill of neonatal nurses at collecting urine specimens, the captive population, less early passage of meconium, and the method used for collection.
Urinary 5C- and 7C-aglycone excretion by term and preterm infants was dose dependent and increased within $24 \mathrm{~h}$ of $\mathrm{K}_{1}$ prophylaxis. The slower increase in excretion over $24 \mathrm{~h}$ after i.m. injection compared with an equivalent dose $(200 \mu \mathrm{g})$ given by the i.v. route (Fig. 3) gives support to a depot effect whereby lipophilic vitamin $\mathrm{K}_{1}$ leaches out only slowly from the muscular site of injection into the circulation. This depot effect has been proposed as the reason why i.m. vitamin $\mathrm{K}$ prophylaxis gives a longer protection against late VKDB than i.v. prophylaxis (26). A rapid urinary elimination after i.v. administration was previously found in adult volunteers given a single i.v. dose of $1 \mathrm{mg}$ tritium-labeled $\mathrm{K}_{1}$ with about $2 \%$ of the dose being excreted within the first $2 \mathrm{~h}$ (27). Significant and sustained increases in the rate of urinary excretion of the 5C and 7C metabolites were also found during a controlled dietary study during which adults increased their $\mathrm{K}_{1}$ intake from $11 \mu \mathrm{g} / \mathrm{d}$ to $206 \mu \mathrm{g} / \mathrm{d}$ (19). In this study, term infants excreted just $0.03 \%$ of a parenterally administered pharmaceutical dose as urinary metabolites within $24 \mathrm{~h}$ in contrast to the $14-20 \%$ of an i.v. dose in adults (27). A relatively inefficient mechanism for the metabolism and excretion of vitamin $\mathrm{K}$ in healthy term newborns is suggested by the prolonged residence time of $\mathrm{K}_{1}$ in blood after oral prophylaxis $(28,29)$; this is in marked contrast to the rapid disappearance from plasma in adults $(27,30)$. A caveat to this study is that we did not measure fecal output of vitamin K metabolites. Studies in adults suggest that $20-30 \%$ of newly absorbed $\mathrm{K}_{1}$ is excreted in the urine and $30-40 \%$ in the feces $(30,31)$. We have been unable to assess whether any shift in excretion between the urinary and biliary routes after vitamin $\mathrm{K}$ prophylaxis could account for the small proportion of vitamin $\mathrm{K}$ excreted as urinary metabolites.

Of the subgroup of 13 preterm infants enrolled into the comparative prophylaxis trial, three infants $(23 \%)$ mainly excreted the $7 \mathrm{C}$-aglycone (relative to the $5 \mathrm{C}$-aglycone), and they all showed raised levels of circulatory $\mathrm{K}_{1} \mathrm{O}$, which is a by-product of Gla synthesis and is usually efficiently salvaged by VKOR to replenish supplies of the GGCX cofactor vitamin $\mathrm{K}$ hydroquinone. With the exception of individuals who have recently received a large pharmacological dose of $\mathrm{K}_{1}$ or those exposed to vitamin $\mathrm{K}$ antagonists (e.g. warfarin), circulatory levels of $\mathrm{K}_{1} \mathrm{O}$ are typically below the detection limit of our assay. Thus, the combination of an increased proportional excretion of the $7 \mathrm{C}$-aglycone together with a raised $\mathrm{K}_{1} \mathrm{O}$ may indicate a metabolic overload of both vitamin $\mathrm{K}$ recycling and catabolic pathways. Further evidence that an increased excretion of the 7C-aglycone is indicative of metabolic overload is provided by the finding that the $7 \mathrm{C}$ metabolite predominated in two of the four infants receiving the higher $500 \mu \mathrm{g}$ dose and in one of the four infants who received $200 \mu \mathrm{g}$ by i.v. injection, whereas the $5 \mathrm{C}$ metabolite was the major product in all preterm infants who received the lower $200 \mu \mathrm{g}$ dose of $\mathrm{K}_{1}$ via the i.m. route. In contrast, we found that the $5 \mathrm{C}$-aglycone was the predominant excretory product in 155 (97\%) of 159 healthy young adults (unpublished data). Infants in this study who mainly excreted the 7C-aglycone also had the highest serum levels of $\mathrm{K}_{1}$ (data not shown). The $7 \mathrm{C}$-aglycone was also the major metabolite in adults supplemented with large 
doses (45 mg) of MK-4 (unpublished data). This pattern may indicate saturation of a component(s) of the $\omega$ - and $\beta$-oxidative enzyme system that carries out degradative side chain shortening of vitamin K before excretion $(18,19)$. The likelihood that some preterm infants are unable to efficiently metabolize current prophylactic doses of vitamin K given at birth is supported by the finding that many preterms in this trial still had grossly elevated circulatory levels of $\mathrm{K}_{1}$ on the fifth day of life that reached concentrations to several 100-fold higher than endogenous concentrations in healthy adults (20). These finding are consistent with previous reports $(11,12)$.

We have shown that the 5C- and 7C-aglycone metabolites of vitamin $\mathrm{K}$ can be determined in urine samples from term and preterm infants, despite markedly reduced rates of excretion relative to adults. Measurement of these metabolites may facilitate the future noninvasive longitudinal study of vitamin $\mathrm{K}$ status in this vulnerable population and may provide further insight into the ability of individual infants to catabolize and use vitamin $\mathrm{K}$ effectively.

Acknowledgments. We thank all parents and infants who participated in this study. We are indebted to the neonatal nurses and midwives at Hope Hospital for their help with this study, in particular for perseverance and diligence in urine collection. We also thank Mark Guy and the staff of the Department of Biochemistry at Hope Hospital, and Donna Roeves, Kieran Voong, and Julia Harvey for their support.

\section{REFERENCES}

1. Suttie JW 2009 Vitamin K in Health and Disease. Taylor \& Francis Group, Boca Raton, FL

2. Shearer MJ, Barkhan P, Rahim S, Stimmler L 1982 Plasma vitamin $K_{1}$ in mothers and their newborn babies. Lancet 2:460-463

3. Haroon Y, Shearer MJ, Rahmin S, Gunn WG, McEnery G, Barkhan P 1982 The content of phylloquinone (vitamin $\mathrm{K}_{1}$ ) in human milk, cows milk and infant formula foods determined by high-performance liquid chromatography. J Nutr 112:11051117

4. Institute of Medicine 2001 Dietary Reference Intakes for Vitamin A, Vitamin K, Arsenic, Boron, Chromium, Copper, Iodine, Iron, Manganese, Molybdenum, Nickel, Silicon, Vanadium, and Zinc. National Academy Press, Washington, DC

5. Itoh S, Onishi S 2000 Developmental changes of vitamin K epoxidase and reductase activities involved in the vitamin K cycle in human liver. Early Hum Dev 57:15-23

6. Bovill EG, Soll RF, Lynch M, Bhushan F, Landesman M, Freije M, Church W, McAuliffe T, Davidson K, Sadowski J 1993 Vitamin $\mathrm{K}_{1}$ metabolism and the production of des-carboxy prothrombin and protein $\mathrm{C}$ in the term and premature neonate. Blood 81:77-83

7. Greengard O 1977 Enzyme differentiation of human liver: comparison with the rat model. Pediatr Res 11:669-676
8. Shearer MJ 2009 Vitamin K deficiency bleeding (VKDB) in early infancy. Blood Rev 23:49-59

9. Ansell P, Roman E, Fear NT, Renfrew MJ 2001 Vitamin K policies and midwifery practice: questionnaire survey. BMJ 322:1148-1152

10. Clarke P, Mitchell S 2003 Vitamin K prophylaxis in preterm infants: current practices. J Thromb Haemost 1:384-386

11. Kumar D, Greer FR, Super DM, Suttie JW, Moore JJ 2001 Vitamin K status of premature infants: implications for current recommendations. Pediatrics 108:11171122

12. Costakos DT, Greer FR, Love LA, Dahlen LR, Suttie JW 2003 Vitamin K prophylaxis for premature infants: $1 \mathrm{mg}$ verus $0.5 \mathrm{mg}$. Am J Perinatol 20:485-490

13. Clarke P, Vitamin K prophylaxis for preterm infants. Early Hum Dev 86:17-20

14. Golding J, Greenwood R, Birmingham K, Mott M 1992 Childhood cancer, intrammuscular vitamin K, and pethidine given during labour. BMJ 305:341-346

15. Fear NT, Roman E, Ansell P, Simpson J, Day N, Eden OB; United Kingdom Childhood Cancer Study Investigators 2003 Vitamin K and childhood cancer: a report from the United Kingdom Childhood Cancer Study. Br J Cancer 89:12281231

16. Andrew M 1997 The relevance of developmental hemostasis to hemorrhagic disorders of newborns. Semin Perinatol 21:70-85

17. Shearer MJ, Barkhan P 1973 Studies on the metabolites of phylloquinone (vitamin $\mathrm{K}_{1}$ ) in the urine of man. Biochim Biophys Acta 297:300-312

18. Harrington DJ, Soper R, Edwards C, Savidge GF, Hodges SJ, Shearer MJ 2005 Determination of the urinary aglycone metabolites of vitamin K by HPLC with redox-mode electrochemical detection. J Lipid Res 46:1053-1060

19. Harrington DJ, Booth SL, Card DJ, Shearer MJ 2007 Excretion of the urinary 5Cand $7 \mathrm{C}$-aglycone metabolites of vitamin $\mathrm{K}$ in response to changes in dietary phylloquinone and dihydrophylloquinone intake. J Nutr 137:1763-1768

20. Clarke P, Mitchell SJ, Wynn R, Sundaram S, Speed V, Gardener E, Roeves D, Shearer MJ 2006 Vitamin K prophylaxis for preterm infants: a randomized, controlled trial of 3 regimens. Pediatrics 118:e1657-e1666

21. Oddie S, Adappa R, Wyllie J 2004 Measurement of urine output by weighing nappies. Arch Dis Child Fetal Neonatal Ed 89:F180-F181

22. Davidson KW, Sadowski JA 1997 Determination of vitamin K compounds in plasma or serum by high-performance liquid chromatography using postcolumn chemical reduction and fluorimetric detection. Methods Enzymol 282:408-421

23. Belle M, Leclercq M, Vignal B, Massignon D, Giovangrandi Y, Missotte I, Brebant R, Shearer M 1995 Application of an ELISA test to vitamin K-deficient conditions using a new monoclonal antibody against human des-gamma-carboxy-prothrombins (DCP). In: Sutor AH, Hathaway WE (eds) Vitamin K in Infancy. Schattauer, Stuttgart, pp. 123-137

24. Belle M, Brebant R, Guinet R, Leclercq M 1995 Production of a new monoclonal antibody specific to human des-gamma-carboxyprothrombin in the presence of calcium ions. Application to the development of a sensitive ELISA test. J Immunoassay 16:213-229

25. Shearer MJ, McCarthy PT, Crampton OE, Mattock MB 1988 The assessment of human vitamin K status from tissue measurements. In: Suttie JW (ed) Current Advances in Vitamin K Research. Elsevier, New York, pp 437-452

26. Loughnan PM, McDougall PN 1996 Does intramuscular vitamin $K_{1}$ act as an unintended depot preparation? J Paediatr Child Health 32:251-254

27. Shearer MJ, Mallinson CN, Webster GR, Barkhan P 1972 Clearance from plasma and excretion in urine, faeces and bile of an intravenous dose of tritiated vitamin $\mathrm{K}_{1}$ in man. Br J Haematol 22:579-588

28. Schubiger G, Tönz O, Grüter J, Shearer MJ 1993 Vitamin $K_{1}$ concentration in breast-fed neonates after oral or intramuscular administration of a single dose of a new mixed-micellar preparation of phylloquinone. J Pediatr Gastroenterol Nutr 16:435-439

29. Schubiger G, Grüter J, Shearer MJ 1997 Plasma vitamin $K_{1}$ and PIVKA-II after oral administration of mixed-micellar or cremophor EL-solubilized preparations of vita$\min \mathrm{K}_{1}$ to normal breast-fed newborns. J Pediatr Gastroenterol Nutr 24:280-284

30. Shearer MJ, Mc Burney A, Barkhan P 1974 Studies on the absorption and metabolism of phylloquinone (vitamin $\mathrm{K}_{1}$ ) in man. Vitam Horm 32:513-542

31. Olson RE, Chao J, Graham D, Bates MW, Lewis JH 2002 Total body phylloquinone and its turnover in human subjects at two levels of vitamin $\mathrm{K}$ intake. Br J Nutr $87: 543-553$ 